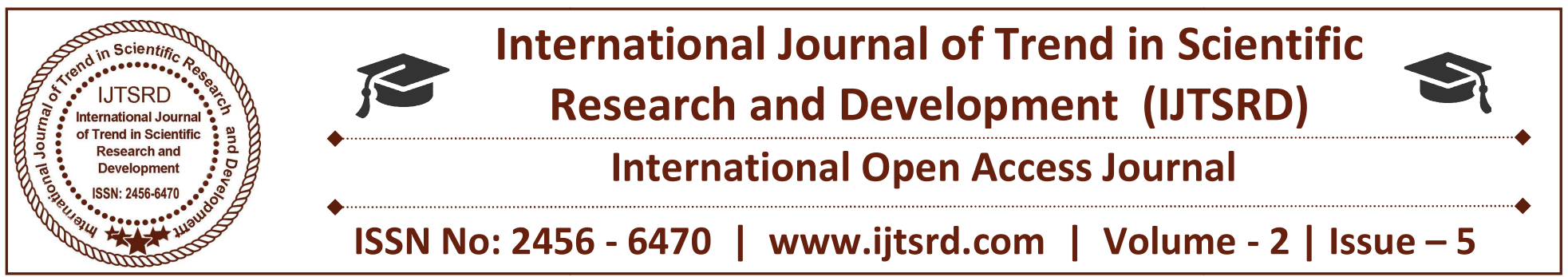

\title{
A Study on Role of Digital Marketing Tools in Women Education, Employment and Empowerment \\ Dr Naveen Kumar ${ }^{1}$, Bindu Tiwari ${ }^{2}$ \\ ${ }^{1}$ Assistant Professor, ${ }^{2}$ Ph.D Student \\ School of Management, Gautam Buddha University, \\ Greater Noida, Uttar Pradesh, India
}

\begin{abstract}
Marketing is all about playing with the mind of people and hitting at right time at right place such that the audience perceive things in same way which a marketer want them to. Yes it is true that the real king of market is customer but at the other side, time and technology added with creative competition has raised an immense need of the unit that is set only to think what customer can think next for and always keep company ready before the market can really demand of it. In this regards that unit of marketing and planning plays a great role in present time to transmit and cover minds of its audience with what they want
\end{abstract} to and how they want to.

This paper will be focusing on the same issue, marketing tools that are all around everyone, near or far in any of the forms in daily basis and directly or indirectly influencing thoughts and actions of people exposed to them. Major objective of this paper will be to analyse efforts of various digital marketing tools in transmitting positive thoughts regarding gender issues and their ways that are assisting in empowering women, changing so called social boundaries and restriction that are set as what women can or cannot do. Paper will be completely based upon the ideas and opinion generated through a deep study of secondary data available under similar topics in journals, newspapers, research papers, online, etc. paper will try to deal with various marketing tools and their efforts in women's carrier advancement promoting girl education, employment and women empowerment eliminating gender discrimination will also be covered individually and their effectiveness due to digitalization of these tools.
Keywords: Digital marketing, women empowerment, gender equity, gender discrimination, digitalization.

\section{INTRODUCTION}

It was the time where work responsibility was divided among two, on the basis of "who can do what better", but with the change in time, people forget about that and thought female are for doing nothing and passing time being at home and all the work responsibility is of male so male can rule female. As time never stops, things got changed and the role got modified. Again, time demands specialization and effectiveness. So now there is no more division on the basis of "who has to do what" but "who can do what in a better way". Female gender has been perceived to be physically and emotionally weak and male gender has been given with the responsibility to protect them. But today, women being successful at the most adventurous and mentally \& physically challenging jobs like in military, airlines, judiciary, politics, journalism, etc. has proved that will power matter more than assumptions made. It is the choice you make for yourself and your dedication to reach there.

At the other side, there lies something called "biological nature", that is in fact different in each gender by birth. Except in exceptional cases, male and females are naturally different in following bases:

\section{Communication:}

Female has got more communication centres inside her brain than of men. It enables her to choose more proper words while communicating and skills to understand body language, facial expressions, 
understand gestures and read between the line in a better way than any ordinary men.

\section{Dependency and problem solving:}

Men are found more independent in problem solving cases than any ordinary female. Men try to solve their problem in their own and don't bother to share it with many mostly. But in contrast to it, female gets distressed if they don't share things and take help or suggestions with others in solving their problem.

\section{Physical attraction:}

Area that is responsible for physical attraction is bigger in men's brain than female, so looks does matter more to men and their priority points physical attractiveness more than any other traits. But female do care other personality traits in addition to looks.

\section{Aggression and diplomacy}

A typical man is found to be more aggressive and with the better ability to recognize angry faces than a typical female. Female are mostly conflict avoiding and keeping peace of mind until any external thing came to happen to shake her original nature.

\section{Thinking process:}

Men are found to be emotionally stronger than female so at the most of situation they can take decisions logically and get done with it. And female considers many emotional aspects related to any decision and get stuck to it for longer period of time.

Due to these inevitable natures of these two different genders they have their own strengths and weaknesses, that some sector needs and some sector doesn't even count. Let us take a glance over the following figure:

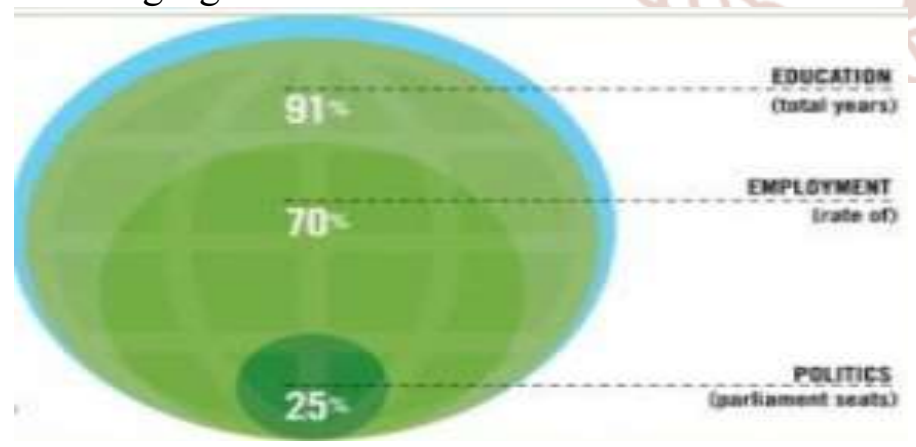

Source: University of Vermont

The figure above by the research over more than 51 country data since many years records, it has been noted that the education gap between gender has been minimized maximum. $91 \%$ of education that male gets has reach of female too. but female gets only $70 \%$ of employment opportunity that male are in reach to. And in politics, the contribution is in minority.

Addition to the advancement in career choices and preference of present day lady, there are some aspects that she never can escape of or any other cannot replace of, i.e. giving birth, extending family, caring and nurturing offspring. Male can only make these less tough to her but cannot do y himself. Thus for life long these things gets more attached to her than him, so she willingly or unwillingly has to manage it and if she thinks of more than, it is added responsibility for her due her own choice of standing in some position and gaining some identity rather than getting lost in a small world called "Home". May be due to same reason they are thought to be less reliable on the basis of her uncertainty of tenure in the job, there has been always a pay gap. It can be clearly seen in the figure below:

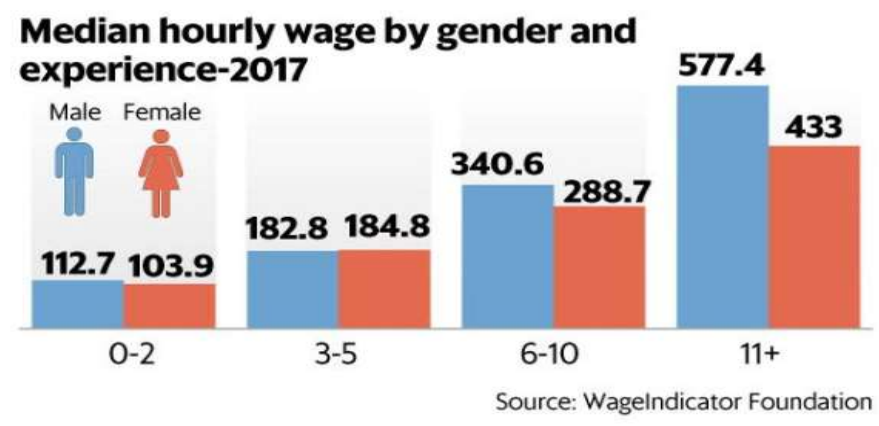

Marketing is a field that needs sharp awareness, diplomacy, sensitivity, flexibility, attentiveness and enormous flow of creativity. This is no more a marketing that was assumed to sell things person to person or door to door at bottom level. Now it is to make things sellable at anyway from anywhere but at the cost of customer satisfaction and in sustainable way.

Internet added to marketing has eradicated so called problems that have been hurdles for women to work, like problem of managing time, security issues to travels long distance, societal issues to express themselves, physical issues for fix and formal work place and timings, etc.

One solution to many problem is digitalization of work, it is synonyms to flexible work place, time, conditions and also pay. Thus digital marketing is now a new attraction that has a long bright future ahead for a career choice to make. But how it is 
assisting in women education, employment and empowerment will be discussed below.

\section{Literature Review}

Jacqueline smith (2013) in an article of Forbes, "The marketing and advertising jobs with great future", notes the influence of marketing efforts and advertising on the daily decision making of people at present times. More literate and working professionals it is sure that they end up having no time to doubt or think of comparing and sparing time to think of certain brands and all. All matters, is impression and first experience. It is easy to get loyal customer but equally difficult to retain them.

In an article by M. Farouk Radwan (2017), in know myself, he discussed difference between a man's and woman's choices and the gender issues which has been raised now is related with lack of understanding between these two genders. He said it is not a problem in itself; it was grown slowly and gradually by us. There is no limitation of possibilities to expand each of them, but the matter is of focus and understanding. "Men and women chooses career differently", an article of The American Interest (2016) reveals that male gets paid $30 \%$ more than the female for same job. It means not only discrimination of contribution worth among different gender but also an act to demotivate female to choose similar career as men do for them. Women are compelled to think differently and inferiorly. Not only at present but since long time back.

A different result is presented in case of millennial, by a report in indeed blog, July, 2016. In this research, indeed found that there is no or very less difference between career choices on the basis of gender. Both the gender are found to be optimistic in getting job of their choices in full time after academic qualification. And also job contents like location, work place, timing, salary, etc. are of equal concern to both of genders.

While we see specifically study marketing field, present scenario is different. A study of Biz Reports, October, 2013 reveals the fact of gender balance in marketing jobs. Additionally they trace a record that initially marketing profession has $3: 1$ ration of female and male employee respectively. But after the age of 30 s rate of female employee taking long break and leaving jobs is very high impacting upon the pay scale of female to male. So top most positions of marketing is acquired by male, while female re-join but take time to regain the position and regain respective level of pay scale.

Apart from these, where a lot of studies are done in women for marketing, there are sufficient studies done about how marketing support women career enhancement. A study presented by University of Texas reveals major 4 reasons how marketing is good for women. First, because marketing is focused for market and market is dominated by women interest, thus marketing job prefer female candidates to male. Second, because women are already in this field with sufficient trace of successful examples. So, they have better credibility and quick acceptance. Third, as women has better ability to understand and imagine than men. So they can get multiple options to be in like product development, strategy development, creative head and even model in any advertisement project. Fourthly, this sector is always moving side by side the sentiments of society, thus the trend and theme changes as per the need of time and situation. And no doubt, it is the time of women empowerment. Digital techniques are very useful to turn things in own way and better way.

\section{Research Objective}

Whole study will be based upon analysing the efforts of various digital marketing tools in women's career advancement. This paper will try to go through each aspect of women's career enhancement (education, employment and empowerment).

\section{Research Methodology}

This paper will be a conceptual paper and will be based upon various secondary information available in different sources like books journals, research papers, newspaper, online articles, etc. Additionally opinions and ideas dragged from the observation of marketing trends will also be presented in paper.

\section{Discussion}

Marketing aims in making things visible and demand generating. There are many tools in marketing that helps in achieving this aim from different ways. As already discussed in introduction part, how a women is more feasible by nature to handle marketing jobs, further how marketing tools support women better will be now discussed. In same reference, firstly let us see following two datas: 

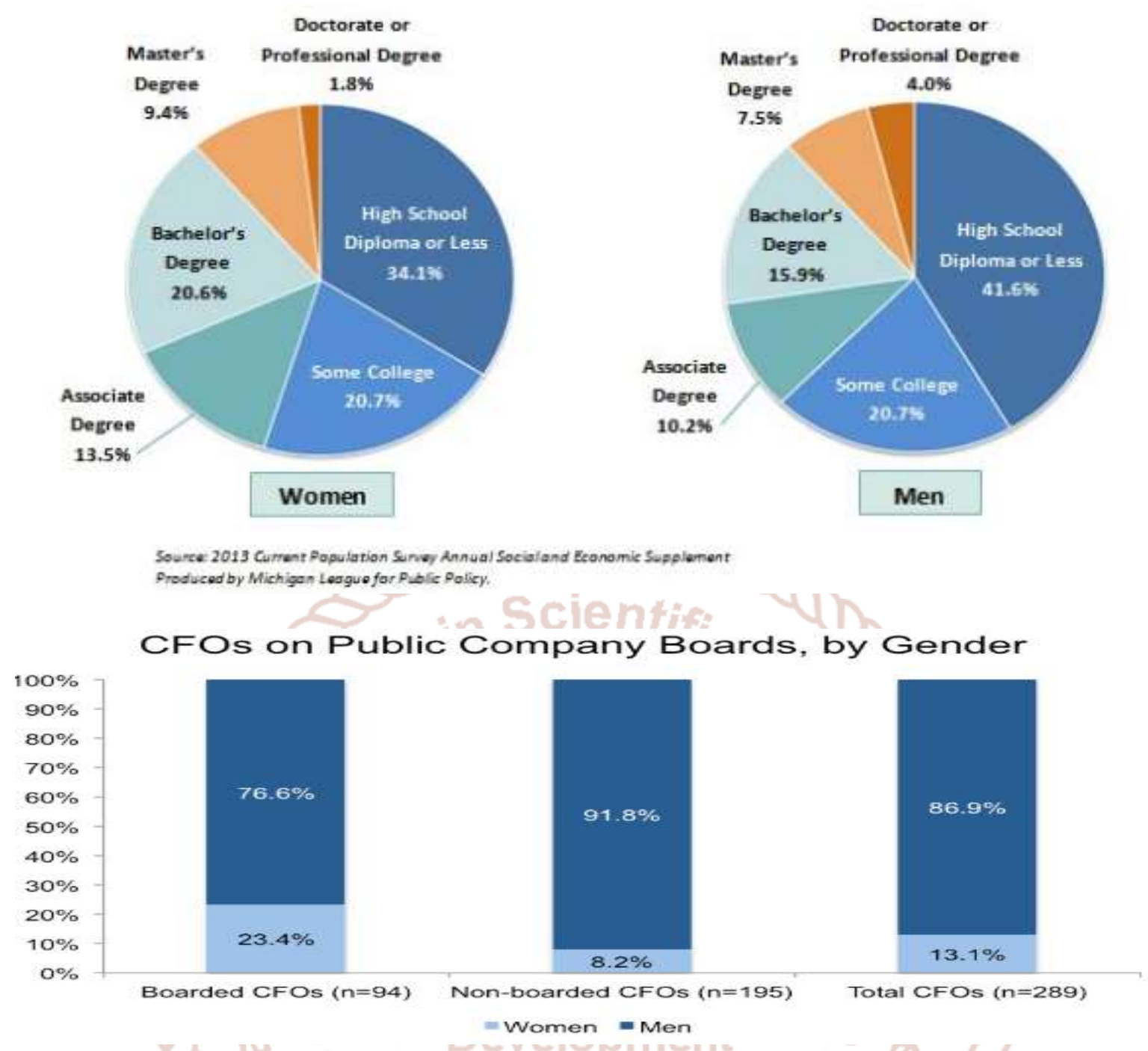

In above two different figures, it shows that education rate of women education after associate degree is higher than of male. But at same time, positions of chief financial officer in most of public company boards are controlled by males. It clearly denotes, only education to women cannot change the whole scenario. While talking about the important factor of women empowerment, it is nothing other than independence. Now, further role of digital marketing in creating independence is explained.

Marketing tools are majorly classified into two categories at present. First is traditional marketing tool and second is digital marketing tool. This paper will discuss both of them relating to their role in women career enhancement. Most of traditional tools have been digitalized in same state and some are added to the list like;

\begin{tabular}{|c|c|c|}
\hline $\begin{array}{c}\text { S. } \\
\text { No }\end{array}$ & $\begin{array}{c}\text { Traditional marketing } \\
\text { tools }\end{array}$ & $\begin{array}{c}\text { Digital marketing } \\
\text { tools }\end{array}$ \\
\hline 1 & Advertisement & Graphic designing \\
\hline 2 & Personal selling & SEO \\
\hline 3 & Public relationship & E-mail marketing \\
\hline 4 & Publicity & $\begin{array}{c}\text { Content Marketing } \\
\text { Social media } \\
\text { marketing }\end{array}$ \\
\hline 5 & Sales promotion & $\begin{array}{c}\text { Marketing } \\
\text { schedule, etc. }\end{array}$ \\
\hline 6 & Direct marketing, etc. & \multicolumn{2}{|c}{} \\
\hline
\end{tabular}

Additional to digitalize traditional marketing tools, added especially digitally developed tools are all easy to learn and effective to implement. 
Advertisement trends have changed its media. It is not only broadcasted through radio or television but also online and in other apps too. But theme of advertisement started being more entertaining that people started responding, searching and sharing those advertisement amongst their network. For women to assist, theme started encouraging women education, equality, right, justice, power, role in society and highlighted her contribution. Women started playing lead roles, heroic activities and achievements are exhibited well.

Personal selling and direct marketing has turned to personalised selling through e-mail, live chats and SMS marketing. For this, there is fair enough chances of employment for both genders for working behind the desk. But it is target based job, thus it came up with flexible working hours and pay for performance. Which is also a motivating factor for women to work in their own time and for own self.

Public relationship is now developed through social media marketing. These assist women to utilize a large network they always are. The sharing and high communicative nature they have makes them easily reach more clients and be visible widely. Publicity is still in hands of media and media is almost $70 \%$ women filled sector. Sales promotion glows as usual in both digital and physical market, i.e. mostly targeted to women being house in charge and decider of what to buy when for what or whom. Thus this is also better understood by a woman and their idea will better work. So it is also beneficial for a woman both ways.

SEO is the best tool proved to be successful, which has made a charm of digital marketing courses that assist women to work creatively from where they are and get paid well. So digital education through digital classes made it easy to reach and implement learning for women. Being on demand, there is significant opportunity of employment.

Content marketing is all about filtering most wanted contents and easily approachable attractive links to reach target customers. Marketing schedule helps in tracing the record of strategies implemented and well planned process for what next. These all digital marketing tools makes marketing job systematic, worthy, flexible, easy to learn, secure career, good pay and at own time and space when used wisely.

\section{Conclusion}

Better understanding capacity of women makes them on demand for marketing jobs, but to note how marketing supports in women education, employment and empowerment. Before concluding let us see the reasons why a women must learn digital marketing:

I. Benefit of flexible working hour

II. Good pay scale

III. Chance to be an entrepreneur

IV. Digital on demand

V. Easy learning

VI. Best ROI

VII. Nothing to loose

After it, it can be said that marketing in digital age is no more a physical pressure and selling things door to door. It is now to make things or present things as such target audience come seeking them. So it has more to do with understanding psychology of customers and dealing with it responsibly.

Digitalization of marketing tools have made them easy learning, which is supporting women education, better employment with good pay scale supports in women employment and financial and intellectual independence makes women empowered. This way digital marketing plays a crucial role in women education, employment and empowerment.

Additionally, digital marketing has added few new concepts like social marketing, green marketing, CSR in their theme, content marketing, etc. which has made marketing more responsible in directing society in a positive way towards growth and sustainability. Women are integral part of society and their development is must in overall growth of the society. Overall comprises of academic, economic and social strength to grow as an independent person with their own status and recognition.

Digitalization has made impact on everyone's life from many aspects. It has made learning more easy and convenient, exposer more wider and unlimited opportunity for talent anywhere. But the awareness of how and where is done by marketing tools. Making female education as requirement and presenting it as their basic right is one of the contribution of digital advertisements in women education. Highlighting success stories of women entrepreneurs and ladies in top positions need of women economic independence 
is reflected and at the same time shaping thoughts of it audience is achieved.

\section{Bibliography}

1. https://www.forbes.com/sites/jacquelynsmith/201 3/03/13/the-marketing-and-advertising-jobs-withthe-best-future/\#40fcb0c83a58

2. https://www.2knowmyself.com/psychological_dif ferences_between_men_and_women

3. http://blog.indeed.com/2016/07/18/do-millennialmen-women-want-same-things-job/

4. http://www.bizreport.com/2013/10/researchreveals-gender-gap-in-top-marketingpositions.html

5. https://www.quora.com/Can-marketing-be-acareer-option-for-women
6. https://degree.utpb.edu/articles/business/4reasons-women-should-consider-a-career-inmarketing.aspx

7. Ms. Ruchi Malhotra1, Empowering Women through Digital Technology: An Indian prospective, International Journal Of Business Management, ISSN NO. 2349-3402, VOL. 2(1),2015

8. Dr. Jyoti Parihar, How Digital India minimised the Great Gender Divide?, Journal Of Humanities And Social Science (IOSR-JHSS) Volume 22, Issue 11, Ver. 8 (November. 2017) PP 29-33

9. Shanmuga Priya S, Dr. Sakthi, Social media a tool for economic empowerment of women, International Journal of Applied Research 2015; 1(5): 157-160 